\title{
The Teaching Reform of Strategies and Skills in Perspective of English Reading: A Case Study of Chinese Mongolian Students
}

\author{
Lili Zhao ${ }^{1}$ \\ ${ }^{1}$ Department of Foreign Language Teaching, Inner Mongolia University for the Nationalities, Tongliao, China \\ Correspondence: Lili Zhao, Department of Foreign Language Teaching, Inner Mongolia University for the \\ Nationalities, Tongliao, China. E-mail: lilingky@163.com
}

Received: November 24, 2014 Accepted: January 8, 2015 Online Published: February 25, 2015

doi:10.5539/ells.v5n1p102 URL: http://dx.doi.org/10.5539/ells.v5n1p102

\begin{abstract}
This thesis discusses some issues commonly observed in English reading. The purpose of the paper is to throw light on issues that arise from students' reading obstacles and put forward some innovative and feasible teaching methodologies to improve the students' reading abilities. A simple survey is conducted by the author, using six question items with each item representing an important issue about English reading in an attempt to explore the most common problems that Mongolian students may meet with during their reading process. These items/issues are as follows: (1) small vocabulary; (2) limited strategies and skills; (3) inadequate culture background knowledge; (4) unable to understand the context; (5) bad reading habits; and (6) lack of Language sense. The paper then discusses each issue one by one and makes some practical suggestions to help address these issues as a way to introduce some innovative teaching methods to give guidance to students. With due consideration of the analysis above, we may draw a conclusion that the teacher should take into account the comprehensive factors that affect English reading and strive for the inspiring teaching strategies to help improve students' reading competence.
\end{abstract}

Keywords: reading, vocabulary, culture, context, reading habits, teaching strategy

\section{Introduction}

Reading in any language is viewed as cognitively demanding, involving the coordination of attention, memory, perceptual processes, and comprehension processes (Kern, 1989). For Chinese Mongolian students, teachers pay more attention to students' basic knowledge, such as vocabulary, sentence patterns, grammar and most often the teacher is likely to explain the text in detail instead of teaching students efficient reading skills to develop their reading abilities. English reading requires not only a good master of vocabulary, but also a great number of reading skills. Many factors have an effect on students' reading abilities, and students may often come across such difficulties as limited vocabulary, lack of cultural background knowledge, bad reading habits and the background information with regard to the context and so on. Therefore, good reading techniques and effective teaching methods are very essential to achieve better reading effects. According to the new curriculum objectives of college English reading, the teacher first discusses some frequently used patterns of reading process and then makes a survy to find out the most common problems that students may meet with. In this way the teacher tries to take advantage of some effective teaching methods to help students develop their reading skills and gain more knowledge by means of reading extensively.

\subsection{The Teaching Objectives of College English Reading}

With a view to keeping up with the new developments of higher education in China, deepening teaching reform, improving teaching quality, and meeting the needs of the country and society for qualified personnel in the new era, College English Curriculum Requirements (Requirements hereafter) has been drawn up to provide colleges and universities with the guidelines for English instruction to non-English major students. As for reading, students should generally be able to read English texts on general topics at a speed of $70 \mathrm{wpm}$. With longer yet less difficult texts, the reading speed should be $100 \mathrm{wpm}$. Students should be able to do skimming and scanning. With the help of dictionaries, they should be able to read textbooks in their areas of specialty, and newspaper and magazine articles on familiar topics, grasping the main ideas and understanding major facts and relevant details. They should be able to understand texts of practical styles commonly used in work and daily life. They are expected to be able to employ effective reading strategies while reading. Because institutions of higher learning 
differ from each other in terms of teaching resources, students' level of English upon entering college, and the social demands they face, colleges and universities should formulate, in accordance with the Requirements and in the light of their specific circumstances, a scientific, systematic and individualized College English syllabus to guide their own College English teaching. As China is a large country with conditions that vary from region to region and from college to college, the teaching of College English should follow the principle of providing different guidance for different groups of students and instructing them in accordance with their aptitude so as to meet the specific needs of individualized teaching

\subsection{Patterns of Reading Process}

(a) When readers make use of their existing knowledge, they have an idea of what the text is about, and use incoming information from the text to confirm or reject their hypotheses as they read along. This is called top-down processing. In the top-down process,readers use their general knowledge about the world, their linguistic knowledge and their common sense to comprehend the reading materials.Their primary purpose is to get the general idea of the passage rather than the mastery of words and phrases that they come across.

(b) When readers don't make use of their existing knowledge and rely only on the information they obtain from the text, it is called bottom-up processing. Readers derive meaning in a linear manner by means of decoding words, phrases and sentences to make sense.

(c) It is our current understanding that interactive processing,which involves both top-down and bottom-up processes during reading, is implicated in normal reading,and that strategies which make use of both processes are necessary for the successful completion of reading tasks.

As for the mongolian students, most of them only know a little of English and they have limited vocabulary as well as a poor grasp of English grammar. Therefore, teachers should give much more weight to the bottom-up decoding process especially with low level foreign language learners.

\section{Methodology}

\subsection{Participants}

Readers usually meet with many problems when they read a passage. The author conducts a self-administered questionnaire survey among 100 students from two classes in an attempt to find out the factors that influence students' reading most often. The students surveyed are all Mongolian students in the university of Inner Mongolia for the nationalities. They are all in the first grade but in different classes. And they have different English levels. Some have a good command of English while others can not master English very well. Through this study, the author aims to get an overall knowledge of the students' reading abilities.

\subsection{Research Design}

The teacher means to search the obstacles that Mongolian students most often suffer from. By means of reading a variety of reading materials, the students have encountered many problems .Then the teacher employs the method of questionnaire to focus on students' reading difficulties. A series of analyses will be conducted, including (a) small vocabulary; (b) limited strategies and skills; (c) inadequate culture background knowledge; (d) unable to understand the context; (e) bad reading habits; and (f) lack of Language sense. In accordance to these data collected, the teacher proposes some available and feasible teaching strategies to deal with students' reading disorder.

\subsection{Procedure}

The survey is made in the following steps.

(a) The teacher collects some typical reading materials that contain much cultural background information, textual knowledge, and thereby require a variety of reading skills and abilities. These reading materials are chosen from newspapers, journals and exercise books. In this way, the teacher tries to find the suitable reading materials for students to test their reading abilities.

(b) The teacher asks students to read these materials and finish the exercises. Then the teacher gathers the mistakes that students often make and investigates the reasons. Afterwards, the teacher gets the conclusion of the difficulties that students encounter when they read and make a list of the reading obstacles from students by means of a table. Let students choose the items in the table to sum up the most common problems that occur during students' reading. The table below is the result of the survey. Look at Table 1 below. 
Table 1. Factors that affect reading

\begin{tabular}{|c|c|c|c|c|}
\hline Items & Yes, very much & Yes & A little & No \\
\hline Small vocabulary & $67 \%$ & $26 \%$ & $7 \%$ & $0 \%$ \\
\hline Limited Strategies and skills & $37 \%$ & $40 \%$ & $19 \%$ & $4 \%$ \\
\hline Inadequate Cultural background knowledge & $14 \%$ & $58 \%$ & $21 \%$ & $7 \%$ \\
\hline Unable to understand the context & $32 \%$ & $49 \%$ & $11 \%$ & $8 \%$ \\
\hline Bad reading habits & $31 \%$ & $36 \%$ & $23 \%$ & $10 \%$ \\
\hline Lack of Language sense & $37 \%$ & $34 \%$ & $23 \%$ & $6 \%$ \\
\hline
\end{tabular}

\subsection{Data Analysis}

From the table above, we can get the conclusion that the biggest difficulty they come across may be the small vocabulary. Knowing vocabulary is important for getting meaning from a text, readers frequently say that they need more vocabulary so that they can understand the meaning of the sentences. On the other hand, $32 \%$ of the students investigated have such experiences that they still can't understand the article completely though there are not so many new words in the article. Therefore, another problem arises: readers need to know different cultures of different countries so as to catch on to the main idea that the context conveys. In addition, limited strategies and skills of reading are other factors that puzzle students. $37 \%$ of the students are deficient in appropriate reading skills. Inappropriate reading methods often result in slow reading and misunderstanding of the passage. Furthermore, in order to achieve better reading effects, readers also need to get rid of their bad reading habits. Last but not least, a lack of language sense confuses the students as well. Therefore, the author is going to discuss the above-mentioned aspects respectively in the following parts and find solutions to these problems.

\section{Factors Affecting English Reading}

\subsection{Small Vocabulary}

Vocabulary plays a very important role in reading. It is frustrating for readers when they discover they can not read effectively because they don't know many of the new words in the reading materials. It seems that the more words a reader knows, the better he is likely to understand a reading comprehension. If a reader has mastered a large vocabulary, he probably can understand reading materials easily. One of the aims of teaching reading is to enlarge students' vocabulary .The teacher often teaches students new words in the form of vocabulary lists or asks students to consult the dictionary. The two teaching methods have separated new words form its context and are not efficient ways for learners to grasp new words. Therefore, a language teacher needs to find other systematic ways of helping learners with vocabulary. In contrast, a systematic approach might devote lesson time to helping learners at each of the following stages of learning vocabulary-when the learners:

- Meet new words and understand their meaning(s) and the ways they are used;

- Practice using the words

- Find ways that help them memorize the words

- Recall and use the words appropriately (Jim Scrivener, p. 74)

Although extensive independent reading offers a good approach to realize new words, English learners are not willing to read because of limited vocabulary. Many students suffer the problem of limited vocabulary. They often complain that there are so many new words that they can't understand the passage well. Researchers have demonstrated a significant link between vocabulary knowledge and reading comprehension. Laufer (1997) pointed out that reading comprehension for both L1 (native English) and L2 (non-native English) students is "affected by textually relevant background knowledge and the application of general reading strategies .... And yet, it has been consistently demonstrated that reading comprehension is strongly related to vocabulary knowledge, more strongly than to the other components of reading" (p. 20). Therefore, it is necessary for readers to know how to employ strategies to deal with the unknown words they encounter when reading. Teachers are also responsible for the students' acquisition of new words. The following suggestions may be feasible to help students achieve their goals.

a) It is the teacher's task to help students develop inferencing strategies, drawing attention to the guidance available and applying it through careful and repeated work. Students should make it clear if it is necessary to understand the exact meaning of an unfamiliar word so as to get a clue of a sentence or a passage. Sometimes, new words are not obstacles to students because students can guess their meanings through the grammatical functions they play. Students can work in pairs to share their insights and build a collective picture of what they 
have been looking for: for example, cognate words; morphological clues such as prefixes denoting size (for example, 'meta-'); or a negative ( for example, 'il', 'dis', 'im'); the function of the phrase or clause in which the word occurs (for example, to give a contrasting opinion or to give a reason); and the learner's prior knowledge of the world (Tricia Hedge, 2002). If we meet an unknown word we should first decide its part in the speech. Then we can look at the clause or sentence containing the unknown word. If the unknown word is a noun, we should find what adjectives describe it and what its collocation is. If the unknown word is a verb, we should find what nouns it goes with or whether it is modified by an adverb. If the unknown word is an adverb, we need to find what verb it modifies. If the unknown word is an adjective, we need to find what noun it modifies. Sometimes, a conjunction like 'but', 'because', 'if' or 'when' or an adverb like 'however' or 'as a result' can signal the relationship between the clause containing the unknown word and other sentences or paragraphs (Richards, 2000, p. 146). In addition, we can guess the meaning of a new word from the context. The procedure of guessing meaning from the context is actually a separate vocabulary strategy: analyzing the parts of a word. Sometimes, when readers meet a multisyllabic word, and they do not know its meaning, they can analyze its meaningful parts and see if the meaningful parts are very useful to them. What's more, students can skip over a number of unknown words because those words will not have a bad effect on students reading comprehension and thus can be neglected.

b) Another skill of obtaining vocabulary is to use a dictionary. With the encouragement of independent learning of students, the dictionary has come into focus as an important classroom and personal resource. Students can refer to the dictionary when they have met a word several times and do not know its meaning, or when they think that a word is important to their overall comprehension of the text. In most cases, students at beginning levels need to use a bilingual dictionary to look up an unknown word as they only know a few words. As their proficiency grows, teachers should require students to use a monolingual dictionary. In this way, students can enlarge and refine their understanding of the vocabulary that they look up. The other benefit is that monolingual dictionaries facilitate the user's ability to paraphrase a word, that is, it can help users associate that word with other words that have similar meanings. In addition, students need to know what information each word entry carries in order to know the appropriate meaning of a word. In any case, students ought to realize that the dictionary has a legitimate place in a sequence of strategies but is best not used automatically as a first resort.

\subsection{Inadequate Cultural Background Knowledge}

The ability of reading comprehension lies not only in the reader's linguistic knowlege but also their general knowledge concerning the reading materials. It is most common that students can not understand the context though they have not met new words. It is closely related to one's background knowledge. The readings are of various kinds, which contain social science articles, natural science articles, travel stories, proses etc. If the reader lacks geographical knowledge, he is unlikely to understand travel stories. If the reader doesn't know much about social life knowledge, it is difficult for him to get the main idea of the passage. Besides, different cultural background information such as historical allusions and technical terms, is an obstacle for students to know well of the given materials. For example, there is a sentence "John can be relied on. He eats no fish and plays the game". From this sentence, we can hardly find the close relationship of the two phrases "eats no fish" and "plays the game" between the prior sentence "John can be relied on". However, the phrase "eats no fish" is an allusion. In the Elizabethan age, the Protestant refused to obey the the custom of Roman Catholic to take fish as the only dish on Friday for the sake of showing their loyalty to the queen. Thus, the expression "eats no fish" carries the meaning of being loyal to someone. While the idiom "plays the game"means "to play fair". It is another way of expressing a person's upright character.

\subsection{Unable to Understand the Context}

More often than not, students fail to understand a sentence that contains no new words at all. Their difficulty in comprehension lies in their inability to understand the utterance-meaning determined by the context where the utterance occurs. Under such circumstances students may find it helpful to put the troublesome sentence in a relevant context of situation familiar to students. For example:

Either John will come or he won't (Levinson, 1983, p. 111)

The literal meaning of the sentence is the repetition of its meaning. But if we put this sentence into the context of situation, we can understand the meaning, and we can help students create such a situation.

Now, let's look at another example: "That guy's got a Midas touch." (He ziran, 1997, p. 178)

In order to comprehend this sentence, students need to know what "Midas touch" means. It means the skill of turning something into gold. 
Though the cultural knowledge is very essential to us, we still need to put the sentence into context. By analyzing the main clue that the context provides, one can figure out what the exact meaning of the sentence is. That is: two businessmen are talking about another person and one of them utters the sentence to mean that the businessman under discussion is very shrewd and has an easy way of making money as if he possessed a Midas touch.

\subsection{Other Factors That Influence Reading}

\subsubsection{Poor Language Sense}

Language sense refers to the sense that students form through the process of using a certain language. If a student acquires correct language sense, he can not only understand the content of the article quickly, but also comprehend its implication. Therefore, students should read more to train their language sense. On the other hand, teachers should give their lessons in English.In addition, trying to read extensively and listening to the tapes are also effective methods to improve students' linguistic sense.

\subsubsection{Bad Reading Habits}

We should form good reading habits. Just as English philosopher-Bacon said "Some books are to be tasted, others are to be swallowed and some few to be chewed and digested". In the three reading methods, the former two methods are related to extensive reading. You just need to get a general idea through extensive reading, and the reading speed is a big problem. First, we have to form correct reading habits. The following lists are about bad reading habits.

a) In order to draw their attention to the article, some students point to the article with their fingers as they read it. Once a new word occurs, they will stop reading. In that case, they can't understand the gist of the article.

b) Some students like to read out aloud when reading, or even if they don't read aloud they will murmur something. Sometimes they think about the pronunciation in their mind, which also affects their reading speed.

c) When a reader meets new words or unfamiliar phrases, he repeats reading them. Some students even think if they can't understand them for the first time, they can read them many times. In that case, they waste a lot of time.

d) In the process of reading, a reader always translates the sentences into his native language to help him understand the meaning. In this way, a reader wastes much time in limited time.

We should try to get rid of the above-mentioned bad reading habits. Firstly, we should draw our attention to the article without stops of repetition. Secondly, students should restrain themselves from reading out or pointing to new words with their fingers or other things. Thirdly, students are supposed to understand the article directly without translating it into their native language.

\subsubsection{Limited Strategies and Skills of Reading}

From the data analysis, we can get the conclusion that students need to master good reading skills. The following tips may give some enlightenment to the students' reading techniques.

a) Skimming. The aim of skimming is to go over the article and get the general idea. In this way, you can also know the structure of the article. When skimming, you should pay attention to the beginning paragraph, the last paragraph, the first sentence of the article and the last sentence. Particularly, you ought to look for signal words. Signal words are summaries of the context of the article.

b) Reading for the underlying meaning. Through reading, you must not only understand the literal meaning, but also the implication. When reading, you can guess the meaning through your own background knowledge or the context. For difficult sentences, you can analyze their grammatical structures so that you can understand them.

\section{Innovative Teaching Strategies in View of English Reading}

Kenneth Goodman (1967) called reading a "psycholinguistic guessing game", and described reading as a selective process in which the information from the text and knowledge the reader brings with him /her to reading are combined. Nuttall (2002) defines that reading strategy is a kind of reading skill that learners use flexibly in reading process in terms of different text characters, different contexts and different purposes.

While for most of the students, their objective of reading is merely to get correct answers and they are short of appropriate reading skills. It is the teacher's duty to help students grasp the key reading strategies, lead them to evaluate the reading materials, deliberate over the information that the contexts contain and gain knowledge from different literacy styles. Teachers can take the following tips to carry out their reading lessons. 
a) Teachers should ask students to read in questions, which is the key to improve their reading ability. Students ought to read passages with inquisitive minds. They need to be engaged with what they are reading. They should ask themselves some questions in the reading process. Only when students are really fired up by the reading context can they actively obtain much more information.

b) More often than not, students can not understand the meaning of a sentence though they know each word in the sentence. In addition to cultural factors, teachers should remind students to pay attention to punctuation, and signal words, for example "but", "while", "that" etc. Besides, students should grasp different figures of speech, such as metaphor, hyperbole and understatement, because these rhetoric methods convey implied meanings of the sentence.

c) Teachers should change the concept of taking students as passive receivers and should regard students as the main body, and constantly exploring students' potentials (Ausubel, 1978). Teachers can guide students during students' reading process. The students' reading process can be divided into three stages: pre-reading, while-reading and post-reading.

1) In the pre-reading process, the teacher may raise some questions to get students think carefully. The teacher can also inroduce some background information and teach students new words, grammar as well as tell them some learning strategies.

2) In the while-reading stage, the students can be divided into several groups and the teacher can assign some reading tasks to each group. The students may try to finish these tasks by discussion and cooperation. And then each group elect one representative to state his opinion on behalf of the whole group. In this way, the students' motivation and interest may be aroused and it usually achieves better teaching effects. Moreover, the teacher should introduce some reading methods such as silent reading, extensive reading and purposeful oral reading so that students can find the right method to do their reading.

3) In the post-reading stage, the teacher can assign the students some tasks for them to continue their studies. The teacher can assign the students some significant communicative activities such as playing games and telling stories. Besides, a writing assignment concerning the reading articles can also be given to students.

d) To be critical about the reading materials is also another quality that students should poccess. Good readers will take advantage of their background knowledge to assess what they are reading. They may also question the author's choice of language, context and organization. During this process, students are more likely to associate their own personal experiences to evaluate the passage's viewpoints. This is a good way to develop their creative thinking (Gu, Hu, Zhang, \& Bai, 2010).

e) It is of great importance for students to finish reading a passage within a limited time and with high accuracy. Therefore, it is very essential for the teacher to cultivate students' good reading habits and improve their reading speed. The teacher may use the formula: " $\mathrm{X} \backslash \mathrm{Y} \times 6=\mathrm{Z}$ " to test the students reading speed. In the formula, " $\mathrm{X}$ " represents the numbers of words in the passage that the students are going to read. "Y" represents conversion factors of reading time (Every ten seconds are identified as one unit). "Z" represents the number of words that a person is able to read in a minute (Nuttall, 1982). Only with high speed and accuracy can students read efficiently.

f) Teachers should cultivate students' reading interest by reading all kinds of articles. Some articles in English reading materials, especially exposition and discussion articles are always lack of fun and they make students feel bored. Yet stories can always arouse readers' interests. Therefore, it's crucial to stimulate students' interests by selecting the right kind of reading contexts to meet the students' needs. The teacher should choose all kinds of reading materials including fairy tales, biography, history or materials about astronomy, geography, news reports, charts, cartoons, notices, advertisements etc. If the students read these articles continuously, they can not only broaden their mind or learn something about culture and science, but also enlarge their vocabulary, enrich their linguistic knowledge and improve their ability of using language. In this way, students may use language proficiently.

\section{Conclusion}

Reading is a psycholinguistic process. Readers (Rs) start with a set of linguistic symbols that have been chosen by writers (Ws) to represent the thoughts that they wish to express. The reading process ends when the readers have interpreted as much of the WS' intended meaning as is relevant to them. So the Ws put their meanings into language and the Rs reconvert the language into meanings (Wedell, 1995). During the reading process, a good command of reading skills is as important as a good grasp of English linguistic knowledge as well as cultural 
knowledge. Chinese students' reading skills are in dire need of improvement. The methods that are mentioned in the paper will help students find their own shortcomings and enhance their reading abilities. Moreover, the paper elaborates the teacher's roles in improving students' reading ability. Teachers should constantly offer new stimulus to satisfy their hunger for knowledge and teachers should be good at creating the context with some heuristic, thoughtful and interesting problems in English reading teaching (Anderson, 2004). Reading is the key to appreciate the maze of knowledge. To some extent, the teachers' guidance and instruction play an important role in students' reading. In addition to these strategies and skills with regard to English reading mentioned above, there are still many methods and skills for us teachers and students to explore. Reading is a complex process. A good mastery of reading skills is actually very necessary for the readers. Nevertheless, some other factors such as individual differences or a person's psychological or emotional aspects should be taken into consideration as well. It is our teachers' duty to take these factors into consideration and try to grope for some feasible teaching strategies to sharpen up the students'reading competencies.

\section{References}

Anderson. (2004). Exploring Second Language Reading: Issues and Strategies. Beijing Foreign Language Press.

Ausubel. (1978). Educational Psychology: A Cognitive View (2nd ed.). Holt McDougal.

Dong, Y. P., \& Li, S. (1999). Factors Affecting English Reading. Journal of Shaanxi Normal University, 28.

Goodman, K. (1967). Reading: A psycholinguistic guess game. Journal of the Reading Specialist, May, 126-135. http://dx.doi.org/10.1080/19388076709556976

Gu, Y. Q., Hu, G. W., Zhang, J., \& Bai, R. (2010). Strategy-Based Instruction: Focusing on Reading and Writing Strategies. Foreign Language Teaching and Research Press.

Hedge, T. (2002). Teaching and Learning in the Classroom. Shanghai Foreign Language Education Press.

Kern, G. R. (1989). Second Language Reading Strategies Instruction: its effect on comprehension and word inference ability. The Modern Language Journal, 24(1), 135-149. http://dx.doi.org/10.1111/j.1540-4781.1989.tb02535.x

Laufer, B. (1997). The lexical plight in second language reading: Words you don't know, words you think you know, and words you can’t guess. In M. H. Long \& J. C. Richards (Series Eds.) \& Coady, J \& Huckin, T. (Vol. Eds.), Second language vocabulary instruction (pp. 20-34). Cambridge: University Press.

Levinson, E. B. (1991). Reading Development in a Second Language: Theoretical, Empirical and Classroom Perspectives. Norwood, NJ: Able Publishing Corporation.

Nuttall, C. (1982). Teaching reading skills in a foreign language. London: Heineman Education Books Ltd.

Nuttall, C. (2002). Teaching reading skills in a foreign language (pp. 48-52). Shanghai Foreign Language Education Press.

Richards, J. C. (2000). From Reader to reading Teacher. Cambridge University Press.

Scrivener, J. (2002). Learning Teaching: A guidebook for English Language Teachers. Shanghai Foreign Language Education Press.

Wedell, M. (1995). Language Teaching and Learning from Theory to Practice. Higher Education Press.

Ziran, H. (1997). School factors affecting China students English reading ability. Journal of PLA in foreign language institute, 6.

\section{Copyrights}

Copyright for this article is retained by the author(s), with first publication rights granted to the journal.

This is an open-access article distributed under the terms and conditions of the Creative Commons Attribution license (http://creativecommons.org/licenses/by/3.0/). 